\title{
Associations Between Dimensions of Job Stress and Biomarkers of Inflammation and Infection
}

\author{
Els Clays, MSc \\ Dirk De Bacquer, PhD \\ Joris Delanghe, PhD \\ France Kittel, PhD \\ Lieve Van Renterghem, MSc \\ Guy De Backer, PhD
}

\section{Learning Objectives}

- Identify, in this study of male employees without clinical coronary heart disease, any associations between parameters of job stress (perceived demands and control, social support at work) and purported biological markers of inflammation.

- Explain whether and how these dimensions of job stress appeared to be related to infections, including some found in previous studies to possibly be associated with cardiovascular disease (CVD).

- Describe possible ways in which perceived job stress might be linked with CVD.

Abstract

Objective: The objective of this study was to examine associations between dimensions of job stress and indicators of chronic inflammation and infection. Methods: Within a subsample from the BELSTRESS study of 892 male subjects free of cardiovascular disease, dimensions of job stress from the job demand-control-support model were related to biomarkers of inflammation (plasma fibrinogen concentrations, high-sensitivity C-reactive protein, and serum amyloid A) and infection (titers against Chlamydia pneumoniae, cytomegalovirus, and Helicobacter pylori). Results: A negative association was found between job control and plasma fibrinogen concentration, independent from age, education, occupation, body mass index, smoking, alcohol consumption, and use of lipidlowering and antihypertensive medication. Higher social support at work was independently related to an increased risk of positive titers against cytomegalovirus. Conclusions: Results confirm previous findings regarding elevated plasma fibrinogen and low job control. (J Occup Environ Med. 2005;47:878-883)

From the Departments of Public Health (Mrs Clays, Dr De Bacquer, Dr De Backer) and Clinical Chemistry, Microbiology and Immunology (Dr Delanghe, Mrs Van Rentgerghem), Ghent University, University Hospital, Ghent, Belgium; and the Laboratory of Epidemiology and Health Promotion, School of Public Health, Free University of Brussels, Brussels, Belgium (Dr Kittel).

This study was supported by the Belgian Federal Public Service Employment, Labor and Social Dialogue, and the European Social Fund.

Els Clays has no financial interest related to this article.

Address correspondence to: Els Clays, MSc, Ghent University, Faculty of Medicine and Health Science, Department of Public Health, UZ-(2)Blok A, De Pintelaan 185, B-9000 Ghent, Belgium; E-mail: els.clays@UGent.be.

Copyright (C) by American College of Occupational and Environmental Medicine

DOI: 10.1097/01.jom.0000171056.22917.ad or many years, psychosocial factors have been suggested as possible intervening elements in the causation of cardiovascular disease (CVD), with occupational stress as a major issue of attention. ${ }^{1-7}$ One of the most influential and widely used models in this field is the job demandcontrol-support (JDCS) model, introduced by Karasek in the 1970s. ${ }^{8,9}$ Because classic risk factors such as blood pressure and blood lipids cannot fully account for the association between job stress and CVD, alternative pathways are explored. Recently, chronic inflammation and infection have been suggested as possible mediating mechanisms. There is growing evidence for the role of inflammatory processes in the development and progression of CVD. ${ }^{10-17}$ Additionally, it is suggested that chronic infections contribute to inflammatory activity and hence to the development of CVD, although results are less consistent. ${ }^{15,16,18-24}$

Given the growing support for the predictive value of inflammatory and, to a lesser extent, infectious parameters regarding CVD, these mechanisms are possible intermediate variables linking psychosocial job stress to elevated risk of CVD. Hence, it is hypothesized that psychosocial stress is associated with markers of inflammation and infection. Excessive job stress could make a subject more susceptible to infection and/or by an altered immune system induce chronic inflammation. Plasma fibrinogen levels have been related to job strain in several studies, but results are not consistent. ${ }^{25}$ The aim of this study is to 
examine cross-sectionally whether dimensions of job stress from the JDCS model relate to biomarkers of chronic inflammation-fibrinogen, C-reactive protein (CRP), and serum amyloid A (SAA) - and infectionChlamydia pneumoniae (CP), Helicobacter pylori (HP), and cytomegalovirus (CMV) - in a sample of 892 males free of clinical coronary heart disease.

\section{Materials and Methods}

\section{Subjects}

The assumed link between occupational stress and markers of inflammation and infection has been tested with data from the BELSTRESS project, a large epidemiologic cohort study about job stress, cardiovascular, and other health issues and sickness absence. ${ }^{26}$ Within 25 large companies or public administrations across Belgium, all workers aged 35 to 59 years were personally invited to participate in the study. Between 1994 and 1998 , a total of 21,419 respondents (16,329 men and 5090 women) completed a questionnaire and underwent a medical examination. A participation rate of $48 \%$ was reached. Within the BELSTRESS project, a casecontrol study was set up in which 446 cases with evidence of coronary heart disease were identified. ${ }^{15}$ Twice this number of subjects were matched on working environment, age, and educational level. Results here are based on this sample of 892 male subjects free of clinical coronary heart disease. These workers were recruited from 13 private companies (55\% of the sample), 4 public administrations (28\%), 6 banks and insurance companies (16\%), and 2 hospitals $(1 \%)$. The sample contains 116 executives (13\%), 402 white collar workers $(47 \%)$, and 343 blue collar workers $(40 \%)$.

\section{Questionnaire}

Dimensions of job stress were assessed using a self-administered questionnaire - the Job Content Questionnaire (JCQ) - that measures
3 dimensions of the job. Psychologic job demands and job control each contain 9 items; social support at work was measured by 8 items (coworker and supervisor support, 4 items each). ${ }^{9,27}$ In case of 1 missing value per (sub)scale concerning the dimensions of demands, control, and support, the mean value that is calculated over the set of remaining valid (sub)scale items for that particular respondent was imputed, picking up 5\% more valid cases at most. Reliability and validity of these scales within the BELSTRESS project have been demonstrated. ${ }^{28}$ The population is divided into 3 groups regarding the scales of job demands, job control, and social support based on the values of the tertiles. The construct of high job strain refers to the combination of high levels of job demands (values above the median) with low levels of job control (values below the median). This category is contrasted to all other possible combinations of levels of job demands and job control. The "iso(lated)-strain" group is composed of participants with high job strain combined with low levels of social support at work (values below the median). The questionnaire also includes information on age, educational level, smoking behavior, alcohol consumption, and use of lipid-lowering and antihypertensive medication.

\section{Biomedical Examination and Analysis of Blood Samples}

Participants were medically examined by trained observers using standardized methods. Body mass index (BMI) was calculated as body weight (in kilograms) divided by the square of the height (in meters). Blood samples were drawn from sitting, nonfasting individuals at the time of their clinical examination. Blood was allowed to clot, centrifuged, and the supernatant serum was kept frozen at $-70^{\circ} \mathrm{C}$ until analysis. Blood was simultaneously collected in tubes containing trisodium citrate for the determination of plasma fibrinogen. Measurements were made by trained technicians. Assessments were made of plasma fibrinogen, SAA, and high-sensitivity CRP concentrations, and of titers against $\mathrm{CP}, \mathrm{CMV}$, and HP. Detailed information about blood analyses has been published elsewhere. $^{15}$

\section{Statistical Analyses}

Given the skewed nature of the distributions of the inflammatory variables plasma fibrinogen, CRP, and SAA, natural logarithm (ln) transformations were performed, which resulted in normal distributions. The relation between dimensions of job stress from the JDCS model and these inflammatory biomarkers was analyzed by means of one-way analysis of variance on the differences in geometric means. A post hoc test (Tukey-HSD) was performed to make pairwise comparisons of the factor level means.

The infectious parameters $\mathrm{CP}$, $\mathrm{CMV}$, and HP were treated as categorical variables, dividing subjects in having either negative or positive titers against these biomarkers. Logistic regression analyses were conducted in which the odds ratios refer to the risks of having positive titers against the infectious biomarkers.

All statistical analyses were performed using SPSS software.

\section{Results}

Sample characteristics for basic variables and job stress dimensions are presented in Table 1. The median for plasma fibrinogen concentration in the population is $314.4 \mathrm{mg} / \mathrm{dL}$ (mean value $320.3 \mathrm{mg} / \mathrm{dL}$ and standard deviation [SD] 68.2), for CRP concentration $0.94 \mathrm{mg} / \mathrm{L}$ (mean value $2.06 \mathrm{mg} / \mathrm{L}$ and $\mathrm{SD} 4.7$ ), and for SAA concentration $2.10 \mathrm{mg} / \mathrm{L}$ (mean value $5.04 \mathrm{mg} / \mathrm{L}$ and $\mathrm{SD} 18.7$ ). As for the infectious parameters, dichotomous categorical variables were created. With respect to $\mathrm{CP}$, the population was divided into $23 \%$ negatives and $77 \%$ positives, with the cut point set at $0.70 \mathrm{U} / \mathrm{mL}$. The cut point 
TABLE 1

Sample Characteristics for Basic Variables and Dimensions of Job Stress $(n=892)$

\begin{tabular}{lc}
\multicolumn{1}{c}{ Characteristics } & $\begin{array}{c}\text { Mean (SD); Median; Percent (n) } \\
\text { or Tertiles }\end{array}$ \\
\hline Age $(\mathrm{yr}):$ mean $(\mathrm{SD})$ & $49.7(5.4)$ \\
Body mass index $\left(\mathrm{kg} / \mathrm{m}^{2}\right)$ : mean (SD) & $26.9(3.6)$ \\
Alcohol $(\mathrm{g} / \mathrm{d}):$ median & 19.9 \\
Current smoking: \% (n) & $35 \%(311 / 892)$ \\
Former smoking: \% (n) & $37 \%(334 / 892)$ \\
Use of lipid-lowering medication: \% (n) & $5 \%(48 / 892)$ \\
Use of antihypertensive medication: \% (n) & $9 \%(79 / 892)$ \\
Low education: \% (n) & $53 \%(473 / 892)$ \\
High education: \% (n) & $20 \%(179 / 892)$ \\
High job strain: \% (n) & $18 \%(164 / 892)$ \\
Iso-strain: \% (n) & $12 \%(107 / 892)$ \\
Job demands & \\
Mean (SD) & $23.3(4.2)$ \\
First tertile & 21 \\
Second tertile & 25 \\
Job control & \\
Mean (SD) & $69.0(12.8)$ \\
First tertile & 66 \\
Second tertile & 74 \\
Social support & \\
Mean (SD) & $22.6(3.8)$ \\
First tertile & 21 \\
Second tertile & 24 \\
\hline
\end{tabular}

SD indicates standard deviation. for CMV was set at $70 \mathrm{U} / \mathrm{mL}$, which results in 53\% negatives and $47 \%$ positives. There are $64 \%$ negatives and $37 \%$ positives on the HP marker; a subject was considered seropositive if either $\operatorname{IgG}$ or $\operatorname{IgA}$ was above $10 \mathrm{U} / \mathrm{mL}$.

Table 2 shows associations between inflammatory biomarkers and JDCS variables. Analyses of variance were performed on the $\ln$ transformed plasma fibrinogen, CRP, and SAA concentrations. A significant negative association was found between job control and plasma fibrinogen concentration, independent from age, educational level (in three categories: low, medium, and high), occupational group (in three categories: executives, white collar workers, and blue collar workers), BMI, smoking status (smoker vs. nonsmoker), alcohol consumption (g/d), use of lipidlowering medication (yes vs. no), and use of antihypertensive medication (yes vs. no). The difference in mean plasma fibrinogen concentra-

\section{TABLE 2}

Association Between In-Transformed Fibrinogen (mg/dL), C-reactive Protein (mg/L), and Serum Amyloid A (mg/l) Values and Dimensions of Job Stress in 892 Males Using Analysis of Variance

\begin{tabular}{|c|c|c|c|c|c|c|c|c|c|}
\hline & \multicolumn{3}{|c|}{ Fibrinogen } & \multicolumn{3}{|c|}{ C-reactive Protein } & \multicolumn{3}{|c|}{ Serum Amyloid A } \\
\hline & $\begin{array}{c}\text { Geometric } \\
\text { Mean }\end{array}$ & $P$ & $P^{*}$ & $\begin{array}{c}\text { Geometric } \\
\text { Mean }\end{array}$ & $P$ & $P^{*}$ & $\begin{array}{c}\text { Geometric } \\
\text { Mean }\end{array}$ & $P$ & $P^{*}$ \\
\hline No & 313.8 & 0.60 & 0.30 & 0.94 & 0.68 & 0.67 & 2.29 & 0.98 & 0.98 \\
\hline Yes & 316.5 & & & 0.98 & & & 2.29 & & \\
\hline \multicolumn{10}{|c|}{ Iso-strain } \\
\hline \multicolumn{10}{|c|}{ Job demands } \\
\hline $\mathrm{T} 1$ & 314.1 & 0.90 & 0.63 & 1.00 & 0.53 & 0.83 & 2.16 & 0.10 & 0.13 \\
\hline $\mathrm{T} 2$ & 315.6 & & & 0.96 & & & 2.56 & & \\
\hline T3 & 313.2 & & & 0.90 & & & 2.25 & & \\
\hline \multicolumn{10}{|c|}{ Job control } \\
\hline $\mathrm{T} 1$ & 318.0 & 0.04 & 0.03 & 0.96 & 0.62 & 0.18 & 2.25 & 0.91 & 0.80 \\
\hline T3 & $323.4 \dagger$ & & & 1.04 & & & 2.51 & & \\
\hline
\end{tabular}

T1, T2, T3 = tertiles of job stress scales.

*Adjusted for age, educational level, occupational group, body mass index, smoking status, alcohol consumption, use of lipid-lowering medication, and use of antihypertensive medication.

$\dagger P<0.05$; results Tukey-HSD post hoc test: significance of difference from first category. 
tion between the group perceiving high and those perceiving low or medium job control reaches borderline significance $(P=0.06)$. Subjects with high social support at work tend to have a higher mean plasma fibrinogen concentration, but this association is not significant when adjusting for covariates. None of the job stress dimensions correlate with mean concentrations of CRP and SAA. were calculated of having positive titers against the infectious biomarkers CP, CMV, and HP (Table 3). Dimensions of job stress are in no
In logistic regressions, the risks

way associated to the risk of scoring positive on $\mathrm{CP}$ and HP in the study population. A positive independent association was found between social support and CMV; participants with low or medium levels of social support at work have approximately $40 \%$ less risk of having positive titers.

\section{Discussion}

Associations between dimensions of job stress from the JDCS model and biomarkers of inflammation and infection were explored in a sample of 892 male subjects free of clinical coronary heart disease. A negative association was found between per-

\section{TABLE 3}

Association Between Dimensions of Job Stress (Risks) and Positive Titers Against Chlamydia pneumoniae, Cytomegalovirus, and Helicobacter pylori in 892 Males Using Logistic Regressions

\begin{tabular}{|c|c|c|c|c|c|}
\hline & & \multicolumn{2}{|c|}{ Unadjusted } & \multicolumn{2}{|c|}{ Adjusted $^{*}$} \\
\hline & & OR & $95 \% \mathrm{Cl}$ & OR & $95 \% \mathrm{Cl}$ \\
\hline \multicolumn{6}{|c|}{ Chlamydia pneumoniae } \\
\hline Job strain† & Yes & 1.15 & $0.74-1.80$ & 1.24 & $0.76-2.01$ \\
\hline Iso-strain† & Yes & 1.21 & $0.71-2.06$ & 1.27 & $0.71-2.28$ \\
\hline \multirow[t]{2}{*}{ Job demandsł } & $\mathrm{T} 2$ & 0.75 & $0.50-1.14$ & 0.83 & $0.53-1.30$ \\
\hline & T3 & 0.94 & $0.63-1.39$ & 1.10 & $0.70-1.72$ \\
\hline \multirow[t]{2}{*}{ Job control } & $\mathrm{T} 1$ & 1.06 & $0.71-1.56$ & 1.08 & $0.68-1.69$ \\
\hline & $\mathrm{T} 2$ & 1.13 & $0.76-1.69$ & 1.18 & $0.76-1.83$ \\
\hline \multirow[t]{2}{*}{ Social support } & $\mathrm{T} 1$ & 1.05 & $0.66-1.66$ & 1.15 & $0.70-1.89$ \\
\hline & $\mathrm{T} 2$ & 0.83 & $0.54-1.28$ & 0.92 & $0.58-1.46$ \\
\hline \multicolumn{6}{|l|}{ Cytomegalovirus } \\
\hline Job strain† & Yes & 1.21 & $0.84-1.74$ & 1.06 & $0.71-1.58$ \\
\hline Iso-strain† & Yes & 1.34 & $0.87-2.06$ & 1.15 & $0.71-1.84$ \\
\hline \multirow[t]{2}{*}{ Job demands $\ddagger$} & $\mathrm{T} 2$ & 0.96 & $0.67-1.37$ & 1.23 & $0.83-1.82$ \\
\hline & T3 & 0.99 & $0.71-1.37$ & 1.25 & $0.85-1.82$ \\
\hline \multirow[t]{2}{*}{ Job control } & $\mathrm{T} 1$ & 1.02 & $0.73-1.42$ & 0.70 & $0.47-1.03$ \\
\hline & $\mathrm{T} 2$ & 0.92 & $0.66-1.29$ & 0.71 & $0.48-1.03$ \\
\hline \multirow[t]{2}{*}{ Social support } & $\mathrm{T} 1$ & 0.62 & $0.42-0.90$ & 0.62 & $0.40-0.94$ \\
\hline & T2 & 0.61 & $0.42-0.88$ & 0.57 & $0.38-0.86$ \\
\hline \multicolumn{6}{|l|}{ Helicobacter pylori } \\
\hline Job strain† & Yes & 0.91 & $0.63-1.32$ & 0.78 & $0.52-1.18$ \\
\hline Iso-strain† & Yes & 0.74 & $0.47-1.16$ & 0.63 & $0.38-1.04$ \\
\hline \multirow[t]{2}{*}{ Job demands $\ddagger$} & T2 & 1.22 & $0.85-1.75$ & 1.08 & $0.72-1.60$ \\
\hline & T3 & 0.84 & $0.59-1.18$ & 0.83 & $0.56-1.22$ \\
\hline \multirow[t]{2}{*}{ Job control } & $\mathrm{T} 1$ & 1.15 & $0.81-1.62$ & 0.93 & $0.62-1.38$ \\
\hline & T2 & 1.08 & $0.76-1.54$ & 0.96 & $0.65-1.42$ \\
\hline \multirow[t]{2}{*}{ Social support } & $\mathrm{T} 1$ & 0.71 & $0.47-1.05$ & 0.70 & $0.45-1.08$ \\
\hline & $\mathrm{T} 2$ & 1.11 & $0.77-1.62$ & 1.15 & $0.77-1.73$ \\
\hline
\end{tabular}

$\mathrm{T} 1, \mathrm{~T} 2, \mathrm{~T} 3 \mathrm{~m}$ tertiles of job stress scales. Reference categories are third tertiles unless stated otherwise.

${ }^{*}$ Adjusted for age, educational level, occupational group, body mass index, smoking status, alcohol consumption, use of lipid-lowering medication, and use of antihypertensive medication.

†Reference category is "no".

$\ddagger$ Reference category is first tertile.

OR indicates odds ratio; $\mathrm{Cl}$, confidence interval. ception of job control and plasma fibrinogen concentration, independent from age, educational level, occupational group, BMI, smoking status, alcohol consumption, and use of lipid-lowering and antihypertensive medication. Higher social support at work was independently related to an increased risk of positive titers against CMV.

Inflammation as a potential mediating mechanisms in the relation between stress and CVD has been extensively elaborated. ${ }^{29,30}$ It has been suggested that perceived job stress may be related to elevated plasma fibrinogen, although results are not consistent. ${ }^{25,31-37}$ In general, the dimension of job control has been more consistently related to fibrinogen concentrations than job demands, which is in line with our findings. ${ }^{35,38-40}$ Fewer studies have been conducted on possible associations between job stress and concentrations of CRP and SAA. Elevated concentrations of CRP have been found in people with higher job demands. ${ }^{41}$ In the Whitehall study, however, no associations were found between plasma levels of CRP and job demands, job control, or social support. ${ }^{42}$ Based on our results, we are unable to show any relation between job stress dimensions and concentrations of CRP and SAA. These biomarkers are believed to be part of the acute phase response that is induced by stress, but stress may not be implicated in the direct induction of CRP and SAA. ${ }^{29}$ Also, it recently has been suggested that the predictive value of CRP with regard to coronary heart disease may have been overestimated in earlier studies. ${ }^{43}$ However, these findings do not imply that the idea of inflammation as a potential mediating mechanism between stress and CVD is not useful. More research is needed, for instance, on the proinflammatory cytokine IL-6. It is believed that psychosocial stress induces neuroendocrine stress responses by stimulation of the hypothalamic-pituitaryadrenal (HPA) axis and thus 
increases circulating levels of IL-6, which in turn is an important regulator of CRP. ${ }^{29,44,45}$

It is hypothesized that the relation between stress and CVD may partly be mediated by an increased susceptibility to infectious disease, although the predictive value of infectious biomarkers regarding coronary heart disease is uncertain. ${ }^{46}$ For a long time, it has been suggested that psychologic distress may be associated with the onset of infectious diseases. ${ }^{47}$ Evidence of a negative association between stress and antibody response to vaccination has been shown. ${ }^{48}$ The scales of job demands and job control, as well as the high strain and isostrain constructs, are not related to the risk of having positive titers against $\mathrm{CP}$, CMV, or HP in our sample. However, higher social support at work was independently related to an increased risk of positive titers against CMV. This is contrary tot expectations because social support has been negatively related to infection in a number of studies. ${ }^{47}$ Further research with larger numbers is needed to clear up this issue.

Participants in this study were not recruited from a representative sample of the active working population in Belgium, which may limit the external validity of the results. However, because the study cohort covers a broad range of companies and occupational groups, it can be expected to contain substantial variation in exposure to job stress. The participation rate of $48 \%$ within the BELSTRESS project is rather low, and hence a selection bias with respect to personal and job related characteristics cannot be ruled out. Unfortunately, no information was collected to elicit the effect of nonresponse. A random selection of eligible employees on the payroll list showed, however, that nonrespondents and respondents had comparable distributions of age and gender. Moreover, the cardiovascular risk profile of the 892 men involved in this study is in line with expectation for a male Belgian working population of that age range.
The main limitation of this crosssectional study is that it does not allow conducting of prospective analyses. It might be that psychosocial job stress has a rather prolonged effect on biomarkers of inflammation and infection. Furthermore, dimensions of job stress were assessed at only one occasion, which results in increased risk of misclassifications as a result of inaccuracy in assessments. ${ }^{49}$ Multiple assessments would also allow to identify situations of chronic or repeated perception of job stress. It has been argued that the progression of infection and inflammatory atherosclerosis is related to stressors that are recurrent or enduring. ${ }^{29,48}$

As a result of their intraindividual variability, the reproducibility of biologic markers is undoubtedly restricted. ${ }^{50-52}$ This probably is particularly the case for plasma levels of CRP and SAA, because these firstclass acute-phase reactants are the most sensitive plasma proteins that indicate inflammatory activity. ${ }^{53}$ It has been suggested that multiple blood samplings of plasma fibrinogen and CRP are required to decrease the contribution of their intraindividual variation. $^{50,52}$

In conclusion, both the perception of job stress as biomarkers of inflammation and infection were measured with rather imprecise methods. As a result of this, the truly existing associations have most likely been underestimated. Therefore, large prospective studies with multiple assessments of exposure and outcome measures are needed to explore possible associations in greater detail.

\section{References}

1. Schnall P, Landsbergis P, Baker D. Job strain and cardiovascular disease. Апnи Rev Public Health. 1994;15:381-411.

2. Bosma H, Marmot M, Hemingway H, et al. Low job control and risk of coronary heart disease in Whitehall II (prospective cohort) study. BMJ. 1997;314:558-565.

3. Hemingway $H$, Marmot $M$. Evidence based cardiology: psychosocial factors in the aetiology and prognosis of coronary heart disease. Systematic review of pro- spective cohort studies. BMJ. 1999;318: 1460-1467.

4. Schnall P, Belkic K, Landsbergis P, et al. Why the workplace and cardiovascular disease? Occup Med. 2000;15:1-6, iii.

5. Belkic K, Landsbergis $P$, Schnall P, et al. Psychosocial factors: review of the empirical data among men. Occup Med. 2000;15:24-46.

6. Karasek R, Theorell T. The demandcontrol-support model and CVD. Occup Med. 2000;15:78-83.

7. Belkic K, Landsbergis P, Schnall P, et al. Is job strain a major source of cardiovascular disease risk? Scand J Work Environ Health. 2004;30:85-128.

8. Karasek R. Job demands, job decision latitude, and mental strain: implications for job redesign. Adm Sci Q. 1979;24: 285-309.

9. Karasek R, Brisson C, Kawakami N, et al. The Job Content Questionnaire (JCQ): an instrument for internationally comparative assessments of psychosocial job characteristics. J Occup Health Psychol. 1998;3:322-355.

10. Ernst E. Fibrinogen: an independent risk factor for cardiovascular disease. $B M J$. 1991;303:596-597.

11. Danesh J, Collins R, Appleby P, et al. Association of fibrinogen, C-reactive protein, albumin, or leukocyte count with coronary heart disease: meta-analyses of prospective studies. JAMA. 1998;279: 1477-1482.

12. Harris T, Ferrucci L, Tracy R, et al. Associations of elevated interleukin-6 and C-reactive protein levels with mortality in the elderly. Am J Med. 1999;106: 506-512.

13. Koenig W, Sund M, Frohlich M, et al. $\mathrm{C}$-Reactive protein, a sensitive marker of inflammation, predicts future risk of coronary heart disease in initially healthy middle-aged men: results from the MONICA (Monitoring Trends and Determinants in Cardiovascular Disease) Augsburg Cohort Study, 1984 to 1992. Circulation. 1999;99:237-242.

14. Danesh J, Whincup P, Walker M, et al. Low grade inflammation and coronary heart disease: prospective study and updated meta-analyses. BMJ. 2000;321: 199-204.

15. De Backer J, Mak R, De Bacquer D, et al. Parameters of inflammation and infection in a community based case-control study of coronary heart disease. Atherosclerosis. 2002;160:457-463.

16. Delanghe J, Langlois M, De Bacquer D, et al. Discriminative value of serum amyloid A and other acute-phase proteins for coronary heart disease. Atherosclerosis. 2002;160:471-476. 
17. Retterstol L, Eikvar L, Bohn M, et al. $\mathrm{C}$-reactive protein predicts death in patients with previous premature myocardial infarction-a 10 year follow-up study. Atherosclerosis. 2002;160:433440.

18. Mendall M. Inflammatory responses and coronary heart disease. BMJ. 1998;316: 953-954.

19. Gupta S. Chronic infection in the aetiology of atherosclerosis-focus on Chlamydia pneumoniae. Atherosclerosis. 1999;143:1-6.

20. Danesh J, Whincup P, Walker M, et al. Chlamydia pneumoniae IgG titres and coronary heart disease: prospective study and meta-analysis. BMJ. 2000;321:208213.

21. Ridker P, Rifai N, Stampfer M, et al. Plasma concentration of interleukin-6 and the risk of future myocardial infarction among apparently healthy men. Circulation. 2000;101:1767-1772.

22. Yudkin J, Stehouwer C, Emeis J, et al. C-reactive protein in healthy subjects: associations with obesity, insulin resistance, and endothelial dysfunction: a potential role for cytokines originating from adipose tissue? Arterioscler Thromb Vasc Biol. 1999;19:972-978.

23. Danesh J, Wong $\mathrm{Y}$, Ward $\mathrm{M}$, et al. Chronic infection with Helicobacter pylori, Chlamydia pneumoniae, or cytomegalovirus: population based study of coronary heart disease. Heart. 1999;81: 245-247.

24. Pasceri V, Cammarota G, Patti G, et al. Association of virulent Helicobacter pylori strains with ischemic heart disease. Circulation. 1998;97:1675-1679.

25. Theorell T. Job stress and fibrinogen. Eur Heart J. 2002;23:1799-1801.

26. Coetsier P, De Backer G, De Corte W, et al. Onderzoeksdesign en instrumentarium van het Belgische JOBSTRESS onderzoek. Theoretische en toegepaste psychologie. 1996.

27. Karasek R. Job Content Instrument: Questionnaire and User's Guide. Los Angeles: University of Southern California; 1985.

28. Pelfrene E, Vlerick P, Mak R, et al. Scale reliability and validity of the Karasek 'job demand-control-support' model in the Belstress-study. Work Stress. 2001; 15:297-313.

29. Black P, Garbutt L. Stress, inflammation and cardiovascular disease. J Psychosom Res. 2002;52:1-23.
30. Strike P, Steptoe A. Psychosocial factors in the development of coronary artery disease. Prog Cardiovasc Dis. 2004;46: 337-347.

31. Davis M, Matthews K, Meilahn E, et al. Are job characteristics related to fibrinogen levels in middle-aged women? Health Psychol. 1995;14:310-318.

32. Ishizaki M, Tsuritani I, Noborisaka Y, et al. Relationship between job stress and plasma fibrinolytic activity in male Japanese workers. Int Arch Occup Environ Health. 1996;68:315-320.

33. Vrijkotte T, Van Doornen L, De Geus E. Work stress and metabolic and hemostatic risk factors. Psychosom Med. 1999; 61:796-805.

34. Riese H, Van Doornen L, Houtman I, et al. Job strain and risk indicators for cardiovascular disease in young female nurses. Health Psychol. 2000;19:429440.

35. Su C. Association between job strain status and cardiovascular risk in a population of Taiwanese white-collar workers. Jpn Circ J. 2001;65:509-513.

36. von Kanel R, Mills P, Fainman C, et al. Effects of psychological stress and psychiatric disorders on blood coagulation and fibrinolysis: a biobehavioral pathway to coronary artery disease? Psychosom Med. 2001;63:531-544.

37. Kittel F, Leynen F, Stam M, et al. Job conditions and fibrinogen in 14226 Belgian workers. Eur Heart J. 2002;23: 1841-1848.

38. Tsutsumi A, Theorell T, Hallqvist J, et al. Association between job characteristics and plasma fibrinogen in a normal working population: a cross sectional analysis in referents of the SHEEP Study. Stockholm Heart Epidemiology Program. J Epidemiol Community Health. 1999;53: 348-354.

39. Ishizaki M, Martikainen $P$, Nakagawa H, et al. Socioeconomic status, workplace characteristics and plasma fibrinogen level of Japanese male employees. Scand $J$ Work Environ Health. 2001;27:287291.

40. Alfredsson L, Hammar N, Fransson E, et al. Job strain and major risk factors for coronary heart disease among employed males and females in a Swedish study on work, lipids and fibrinogen. Scand $J$ Work Environ Health. 2002;28:238-248.

41. Schnorpfeil P, Noll A, Schulze R, et al. Allostatic load and work conditions. Soc Sci Med. 2003;57:647-656.
42. Hemingway H, Shipley M, Mullen M, et al. Social and psychosocial influences on inflammatory markers and vascular function in civil servants (The Whitehall II study). Am J Cardiol. 2003;92:984-987.

43. Danesh J, Wheeler J, Hirschfield G, et al. C-reactive protein and other circulating markers of inflammation in the prediction of coronary heart disease. $N$ Engl J Med. 2004;350:1387-1397.

44. Zhou D, Kusnecov A, Shurin M, et al. Exposure to physical and psychological stressors elevates plasma interleukin 6: relationship to the activation of hypothalamic-pituitary-adrenal axis. Endocrinology. 1993;133:2523-2530.

45. Yudkin J, Kumari M, Humphries S, et al. Inflammation, obesity, stress and coronary heart disease: is interleukin-6 the link? Atherosclerosis. 2000;148:209214.

46. Danesh J, Whincup P, Lewington S, et al. Chlamydia pneumoniae $\operatorname{IgA}$ titres and coronary heart disease-prospective study and meta-analysis. Eur Heart J. 2002;23:371-375.

47. Cohen S, Williamson GM. Stress and infectious disease in humans. Psychol Bull. 1991;109:5-24.

48. Burns V, Carroll D, Ring C, et al. Antibody response to vaccination and psychosocial stress in humans: relationships and mechanisms. Vaccine. 2003;21:25232534.

49. Landsbergis $P$, Schnall P, Pickering T, et al. Validity and reliability of a work history questionnaire derived from the Job Content Questionnaire. J Occup Environ Med. 2002;44:1037-1047.

50. de Maat M, de Bart A, Hennis B, et al. Interindividual and intraindividual variability in plasma fibrinogen, TPA antigen, PAI activity, and CRP in healthy, young volunteers and patients with angina pectoris. Arterioscler Thromb Vasc Biol. 1996;16:1156-1162.

51. De Bacquer D, De Backer G, Braeckman $\mathrm{L}$, et al. Intra-individual variability of fibrinogen levels. J Clin Epidemiol. 1997;50:393-399.

52. Ockene I, Matthews C, Rifai N, et al. Variability and classification accuracy of serial high-sensitivity C-reactive protein measurements in healthy adults. Clin Chem. 2001;47:444-450.

53. Yamada T. Serum amyloid A (SAA): a concise review of biology, assay methods and clinical usefulness. Clin Chem Lab Med. 1999;37:381-388. 